\title{
Ileal Adenomyoma: Extremely Rare Cause of Intussusception
}

\author{
Abdulkerim Temiz' ${ }^{1}$ Hacı Ali Kahya ${ }^{2}$ \\ ${ }^{1}$ Clinic of Pediatric Surgery, Amasya Sabuncuoğlu Şerefeddin State Hospital, Amasya, Turkey \\ ${ }^{2}$ Clinic of Pathology, Amasya Sabuncuoğlu Şerefeddin State Hospital, Amasya, Turkey
}

\begin{abstract}
Adenomyoma of the gastrointestinal tract is a benign tumor that is usually found in the stomach and is occasionally found in the duodenum and biliary tract; however, it is very rarely found in the small intestine. Adenomyomas of the small intestine that usually present with intussusception are very rare in children. In this study, a case of ileal adenomyoma presenting with intussusception was described. (Eurasian J Emerg Med 2015; 14: 207-8)
\end{abstract}

Keywords: Child, ileum, adenomyoma, intussusception

\section{Introduction}

Adenomyoma is a rare benign tumor of the gastrointestinal system (1-4), also called as foregut choristoma, hamartoma, myoepithelial, or adenomyomatous hamartoma $(3,5)$. It is mostly located in the stomach, duodenum, or biliary tract and very rarely located in the small intestine $(1,3,5,6)$. Adenomyoma of the small intestine, frequently presenting with intussusception, is extremely rare in children; only 14 cases have been reported in the literature. In this case report, we present a case with adenomyoma of the ileum presenting with intussusception.

\section{Case Presentation}

Physical examination of an 11-year-old boy who was admitted to the hospital with abdominal pain that started 2 days ago revealed tenderness, defense, and a mass lesion in the right lower quadrant of the abdomen. Complete blood count was as follows: hemoglobin level: $12.4 \mathrm{~g} / \mathrm{dL}$, hematocrit level: $34.6 \%$, and white blood cell count: 16700 cell $/ \mathrm{mm}^{3}$.

An erect abdominal radiograph showed air-fluid levels in the right lower quadrant of the abdomen and in the paraumbilical region (Figure 1). Although target sign suggesting intussusception was observed in the ultrasound, cecum and colon appeared to be normal. The patient was taken for surgery with a pre-diagnosis of intestinal obstruction and intussusception, and ileoileal intussusception was determined. Manual reduction was performed; however, it was observed that at a distance of approximately $50 \mathrm{~cm}$ proximal to the ileocecal valve, circulation of an approximately $30-\mathrm{cm}$ ileal segment was impaired and not improved after reduction. A solid intramural mass of size $1 \times 1.5 \mathrm{~cm}$ was observed at the anti-mesenteric border of the ileum, approximately $80 \mathrm{~cm}$ proximal to the ileocecal valve at the upper part of the same segment (Figure 2). Mass was excised along with the ileal segment with impaired circulation. End-to-end anastomosis was performed. The pathological examination of the mass was reported as adenomyoma of the small intestine. The patient provided informed consent to publish this case report.

\section{Discussion}

Adenomyoma that is a rare benign tumor of the gastrointestinal system is located in the small intestine in few cases. In the published English literature, the lesion was located in the ileum in approximately $75 \%$ of pediatric patients in whom the site of the lesion was determined, and Meckel's diverticulum was identified in $16.6 \%$ of them $(1-4,7)$. Adenomyoma located in the small intestine most frequently present with intussusception. It may rarely cause ileus, and can be detected incidentally (1-4). As the mass is small, none of the cases has been reported to be identified by imaging methods before surgery. However, the cases may be identified by direct radiographies if adenomyomas cause ileus, and intussusception is identified by the target sign on performing ultrasound $(3,5-7)$. Although the mass was not located in the intussuscepted segment in the case presented herein, 


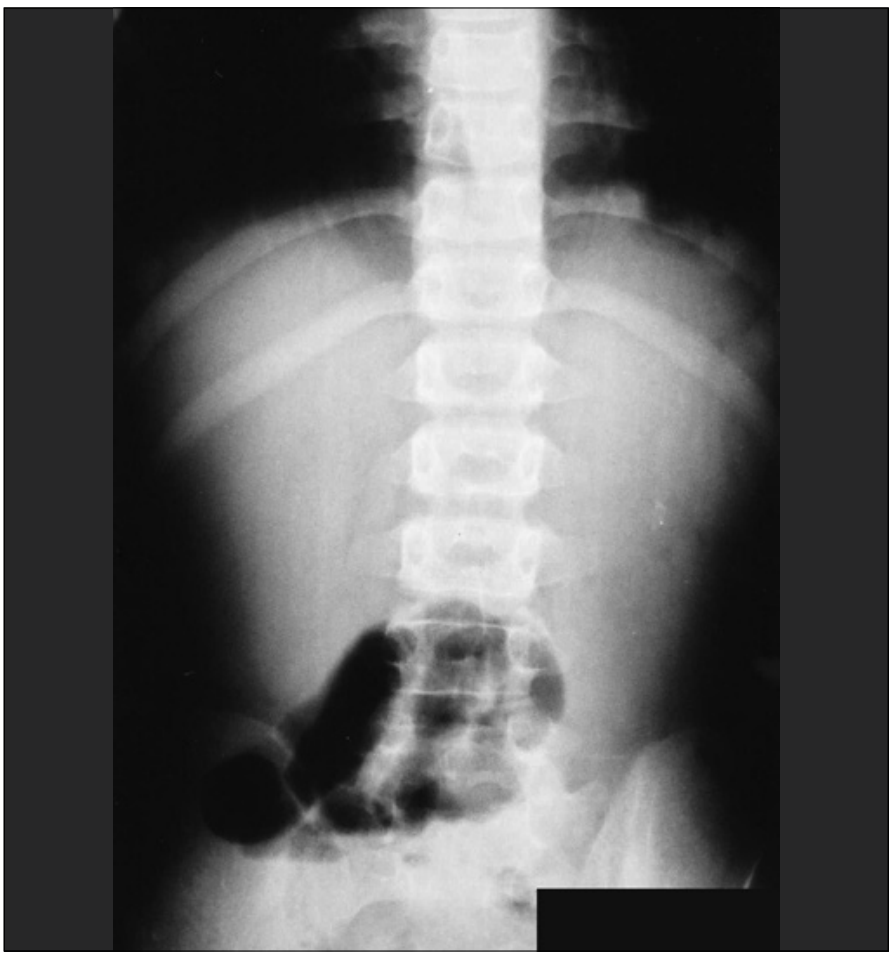

Figure 1. Erect abdominal radiograph showing localized air-fluid levels in the right lower quadrant of the abdomen and in the paraumbilical region

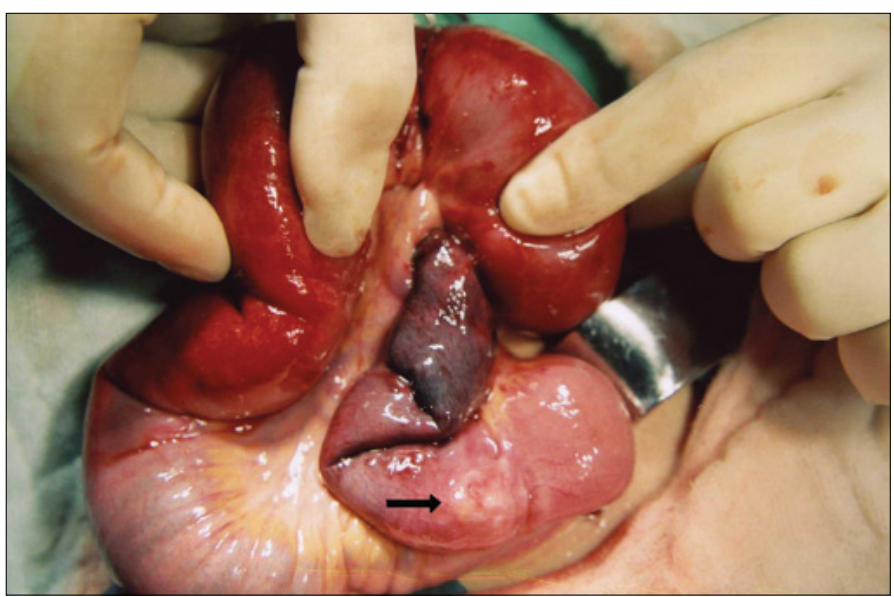

Figure 2. A solid intramural mass of size $1 \times 1.5 \mathrm{~cm}$ at the antimesenteric border of the ileum in the upper part of the invaginated segment

it was identified by the intussusception that it caused. Though the mass was not located in the invaginated segment, we believe that the mass was the triggering factor for intussusception because we failed to observe any other pathological finding that might be considered as "leading point" in the segment. Although not observed in the present case, the site of the lesion matched with the location of Meckel's diverticulum. Adenomyoma is thought to be originated from embryonic epithelial residues (5).

Histopathologically, resembling that of the pancreas or biliary tract, glands with long cylindrical epithelial cells and smooth muscle cells surrounding these glands are seen $(1,3,5)$. The lesion is predominantly located in the submucosa $(4,6)$. Adenomyoma is differentiated from entities with similar macroscopic characteristics including enteritis cystica profunda, pneumatosis cystoides intesti- nalis, metastatic adenocarcinoma, and hamartomatous polyps of the Peutz-Jeghers syndrome based on histopathological criteria (1-4). Differential diagnosis is important to prevent unnecessary radical surgical resections $(2,3)$.

In the light of this information, the reason why adenomyoma is defined as a rare lesion might be because of the fact that it is not considered to be important by the surgical team or pathologists as it is a benign lesion or because of the lack of experienced pathologists to make its diagnosis $(2,7)$.

In the published small intestine adenomyoma cases, diagnostic imaging examinations performed before surgery to identify the lesion have been insufficient. The findings with regard to the complications indicate that the causes of lesions have been determined. Similarly, in the present case, no findings suggestive of adenomyoma could be detected in the diagnostic examinations performed before surgery, and the lesion was diagnosed during surgery.

Total excision of the lesion is adequate in the treatment of benign adenomyoma cases. It will be useful to keep in mind that masses identified in small intestine intussusception cases may play a role as the "leading point," particularly in older children. To make a definite diagnosis, pathological examination of the excised tissues should necessarily be performed.

\section{Conclusion}

Ileal adenomyoma is a very rare intestinal tumor in older children. It may be detected as the pathologic lead point in intussusceptions. Pathological examination of all excised tissues may increase the rate of this clinical entity.

Informed Consent: Written informed consent was obtained from patient who participated in this case.

Peer-review: Externally peer-reviewed.

Conflict of Interest: No conflict of interest was declared by the authors.

Financial Disclosure: The authors declared that this study has received no financial support.

\section{References}

1. Park HS, Lee SO, Lee JM, Kang MJ, Lee DG, Chung MJ. Adenomyoma of the small intestine: report of two cases and review of the literature. Pathol Int 2003; 53: 111-4. [CrossRef]

2. Yao JL, Zhou H, Roche K, Bangaru BS, Ginsburg H, Greco MA. Adenomyoma arising in a meckel diverticulum: case report and review of the literature. Pediatr Dev Pathol 2000; 3: 497-500. [CrossRef]

3. Mouravas V, Koutsoumis G, Patoulias J, Kostopoulos I, Kottakidou R, Kallergis $\mathrm{K}$, et al. Adenomyoma of the small intestine in children: a rare cause of intussusception: a case report. Turk J Pediatr 2003; 45: 345-7.

4. Lee JS, Kim HS, Jung JJ, Kim YB. Adenomyoma of the small intestine in an adult: a rare cause of intussusception. J Gastroenterol 2002; 37: 556-9. [CrossRef]

5. Kim CJ, Choe GY, Chi JG. Foregut choristoma of the ileum, (adenomyoma)--a case report. Pediatr Pathol 1990; 10: 799-805. [CrossRef]

6. Serour F, Gorenstein A, Lipnitzky V, Zaidel L. Adenomyoma of the small bowel: a rare cause of intussusception in childhood. J Pediatr Gastroenterol Nutr 1994; 18: 247-9. [CrossRef]

7. Chan YF, Roche D. Adenomyoma of the small intestine in children. J Pediatr Surg 1994; 29: 1611-2.[CrossRef] 